\title{
Student's Conceptions in Statistical Graph's Interpretation
}

\author{
Ida Kukliansky ${ }^{1}$ \\ ${ }^{1}$ Ruppin Academic Center, Israel \\ Correspondence: Ida Kukliansky, Ruppin Academic Center, Israel. E-mail: idakuk@ruppin.ac.il
}

Received: September 28, 2016

Accepted: October 25, 2016

Online Published: November 2, 2016

doi:10.5430/ijhe.v5n4p262

URL: http://dx.doi.org/10.5430/ijhe.v5n4p262

\begin{abstract}
Histograms, box plots and cumulative distribution graphs are popular graphic representations for statistical distributions. The main research question that this study focuses on is how college students deal with interpretation of these statistical graphs when translating graphical representations into analytical concepts in descriptive statistics. This study is divided into two parts. The research sample included 256 college students in the first part and 187 college students in the second part. The research tools were questionnaires dealing with the interpretation of the graphs, while relating the graphs and other concepts in descriptive statistics. In spite of the benefits learners may reap from using multiple representations, the results reveal that some of the students had difficulties in relating multiple representations to the same data. Educators have to take into account that only deep understanding of each and every one of the representations and their inter-relation will enable students to translate successfully one format into another. Some of the mistakes students made could be derived from the use of the intuitive rule known as the Same A-Same B.
\end{abstract}

Keywords: Higher education, Statistical graphs, Multiple representations, Intuitive rules

\section{Introduction}

The interpretation of data and graphs are central practices in science (Bowen \& Roth, 2005). Due to their importance, graphs can be considered the cornerstone of data analysis (Eshach \& Kukliansky, 2016). Faced with growing abundance of graphic representation in research articles, newspapers and the internet, today's students are expected not only to build various graphs, but also to know how to interpret them. Interpretation of graphs is considered an essential part of statistical literacy (Gal, 2002; Gal, 2004; Watson, 2006; Aoyama, 2007).

The current body of knowledge suggests that although students are often able to draw graphs, they frequently perform poorly on graph interpretation. The present study focuses on how students are dealing with interpretation of statistical graphs such as box plots, histograms and cumulative frequency distribution graphs.

A link between different representations of the same data is required in the process of the graph's interpretation. Many studies highlight the benefits learners may reap from using multiple representations. To name a few, Ainsworth (1999) argued that a known representation may help understand an unknown representation, and that representations may complement each other. Petre, Blackwell and Green (1998) explained that mentally moving between representations forces learners to look beyond the borders and details of a certain representation; Dori and Sasson (2008) found that the ability to move back and forth between representations improved both graphic and conceptual abilities of learners. On the other hand, working within a multi-representational learning environment may pose a difficult challenge for learners in linking representations and moving flexibly between them (Even, 1998; Hong, Thomas and Kwong, 2000; Kukliansky \& Eshach, 2014). Van der Meij and de Jong (2006) argued that a multiple representation environment requires the following: 1) understanding the syntax of each of the representations, 2) understanding which part of the topic is being represented, 3) identifying partial correspondence between representations, and 4) translating between representations by finding the similarities and differences in the two systems of representation. According to Ainsworth (2008), "multiple representations are powerful tools to help learners develop complex scientific knowledge. But like all powerful tools, they require carefully handling and often considerable experience before people can use them to their maximum effectiveness." Construction of mental representations while analyzing graphical representations includes information selection and information organization, parsing of symbol structures, mapping of analog structures as well as model construction and model inspection (Schnotz \& Bannert, 2003). Different levels of mental representations are needed in the process of the graph's interpretation. According to Friel, Curcio and Bright (2001), the three levels of graph sense are: (a) reading 
the data-questions that are supposedly answered on the graph, (b) reading between the data- interpolating and finding relationships in the data presented in a graph and (c) reading beyond the data-extrapolating or inferring from the graph in order to solve complicated questions.

Some of the mistakes made by the students interpreting graphs can be explained by the use of intuitive rules that are developed by learners and help them to solve different tasks in math and science. These rules are considered to be intuitive (Stavy et al., 2006) because the students see such explanations as self-evident and sufficient. Based on extensive observations, Stavy and Tirosh (2000) found that many alternative conceptions are connected to the use of the following intuitive rules:

Same A-Same B: This intuitive rule is employed when comparing two systems $(1,2)$. a) Each of the systems has two features - A and B. It is known that feature A is identical in both systems (A1=A2), thus it is intuited that feature B will also be identical (B1=B2). The rule is sometimes correct and sometimes not.

b) More A-More B: This intuitive rule is employed when comparing two systems $(1,2)$. Each of the system has two features - A and B. It is known that A1>A2, thus it is intuited that the same relation holds also for feature B, meaning $\mathrm{B} 1>\mathrm{B} 2$. In cases where the relation is different, using this rule will lead to an error.

The approach of intuitive rules has recently been supported by brain imaging studies and reaction time research (Babai, Brecher, Stavy \& Tirosh, 2010).

As mentioned before, this quantitative study refers to the interpretation of graphs that students learn in descriptive statistics. It is divided into two parts. Specifically, in each part we address a single research question:

Part I: How do college students deal with interpreting box plots and histograms when translating graphical representations into analytical concepts in descriptive statistics?

Part II: How do college students deal with interpreting cumulative frequency distribution graphs while referring to the three levels of graph sense?

\section{Methods}

\subsection{Part I: the Research Tool and Participants}

The research tool was a questionnaire of nine true/false items dealing with the relation between a) two box plots and b) two histograms, and other associated concepts in descriptive statistics. The questions referred to: two box plots having the same ranges but different medians and interquartile ranges; two symmetric histograms for data having the same average but different standard deviations as shown in Figure 1.
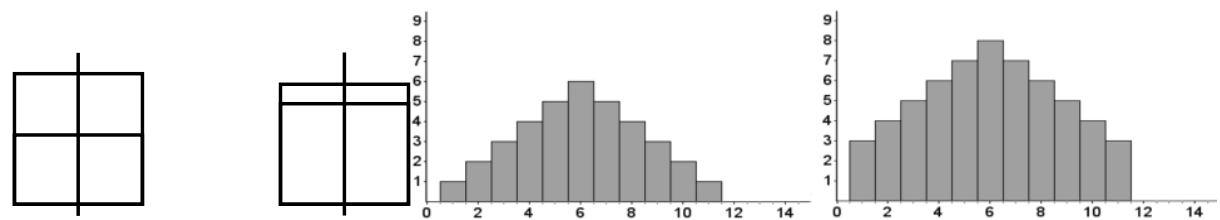

Figure 1. The histograms and box plots

The questions (referred to in the Results section) for the box plots and for the histograms were presented to the subjects in a random order.

The research sample included 256 college students, 85 of them studying business administration and 171 studying economics. The questionnaire was a part of their final exam, so the students' study habits and motivation were as high as one could possibly expect.

\subsection{Part II: the research Tool and Participants}

The research tool for part II included a questionnaire of 8 true-false items, 4 of them examining the (a) level, 2 of them examining the (b) level and 2 of them examining the (c) level of graph sense understanding. All of the items referred to the same cumulative frequency distribution graph (Figure 2, "less than " type) where the X axis showed the number of hours that people spend on the internet and the $\mathrm{Y}$ axis the cumulative number of people. 


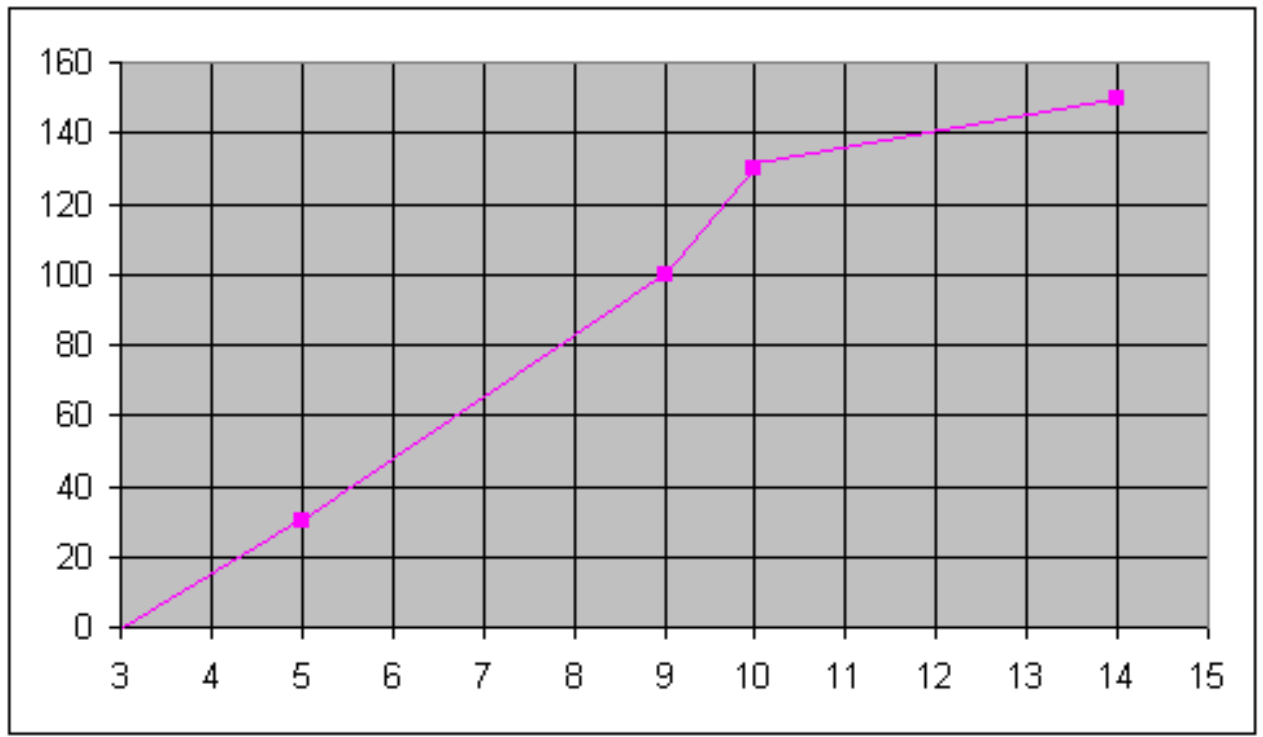

Figure 2. The cumulative frequency distribution graph

As in the previous part, the questionnaire was a part of the final exam. The questions in the questionnaire were arranged randomly.

The participants of the Part II were 187 college students: 98 of them studying business administration and 89 of them studying marine sciences.

\section{Results}

\subsection{The Results of Part I}

The students were presented with two box plots having the same data range, but different dispersion. The average of correct answers for the five box plot items was $83.6 \%$. The students were presented with four items related to the two histograms for symmetrical data having the same average but different dispersion. The average of right answers for the histogram items was $72.5 \%$. The items and the percentage of right answerers for each of them are shown below in Table 1:

Table 1. The percentages (\%) of correct answers for all of the items in the two groups

The items, (T)-true item, (F)-false item

Business Econonomics

administration

1. (T) The interquartile range of data in box plot (1) is higher than in box plot (2). 71

74

2. (T) The median of the data in box plot (2) is higher than in box plot (1)

3. (F) The distribution of the data in box plot (1) is positively skewed and the 80 distribution of the data in box plot (2) is negatively skewed

4. (F) The range of data in both box plots is identical, so they have the same 86 averages

5. (F) The range of data in both box plots is identical, so they have the same 95 standard deviations

6. (T) The averages of data in both histograms are identical and the standard 42 deviation of data in histogram (2) is higher than in histogram (1)

7. (F) The average of data in histogram (2) is higher than in histogram (1) and the 75 standard deviation of data in histogram (1) is higher than in histogram (2)

8. (T) The median of the data in histogram (2) is higher than in histogram (1) 
The average percent of correct answers was $77.1 \%$ for the business administration students and $79.4 \%$.for those who studied economics. The t-test for related samples revealed significant differences between the mean percentage of correct answers between the business administration and economics students $\left(\mathrm{t}(8)=2.48\right.$, $\left.{ }^{*} \mathrm{p}<0.05\right)$. The most difficult question for the students of both groups required the evaluation of the data dispersion from the histogram. The hypothesis of guessing $(\mathrm{p}=50 \%)$ was tested and rejected for each of the nine items $(* \mathrm{p}<0.05)$.

\subsection{The Results of Part II}

Table 2 presents the percentages (\%) of correct answers for all of the items in the two student groups referring to the three levels of graph sense: (a) reading the data, (b) reading between the data and (c) reading beyond the data.

Table 2. The percentages (\%) of correct answers for all of the items in the two groups

\begin{tabular}{lll}
\hline The item's level, (T)-true item, (F)-false item & $\begin{array}{l}\text { Bissuness } \\
\text { administration }\end{array}$ & $\begin{array}{l}\text { Marine } \\
\text { studies }\end{array}$ \\
\hline 1. (a) The median time of surfing the internet is 6 hours daily (F) & 85 & 86 \\
2. (a) 100 people surf the internet more than 9 hours daily (F) & 79 & 85 \\
3. (a) $30 \%$ of the people surf the internet up to 5 hours daily (F) & 87 & 90 \\
4. (a) 130 people surf the internet up to 10 hours daily (T) & 89 & 92 \\
5. (b) 110 people surf the internet between 5 and 12 hours daily (T) & 75 & 80 \\
6. (b) The number of people surfing the internet between 10 and 15 hours is & 71 & 77 \\
smaller than the number of people surfing the internet between 9 to 10 hours & & \\
(T) & 60 & 65 \\
7. (c) The average time of surfing the internet is 7.567 hours daily (T) & 60 \\
8. (c) The distribution of the time surfing the internet daily is positively & 62 & 62 \\
skewed (F) & &
\end{tabular}

The average percentage for the cumulative frequency distribution items for all the participants was $78 \%: 80.1 \%$ for the marine science student and $76 \%$ for the business administration students.

A non-significant Levene's test for equality of variances indicated that the variances of the right answer percentages for the three levels were equal $(\mathrm{F}=1.17, \mathrm{p}=0.39, \mathrm{p}>0.05)$. The two-way ANOVA revealed significant differences between the mean percentage of right answers for the three levels $(\mathrm{F}=742.78, * * * \mathrm{p}<0.001)$. The post-hoc multiple comparisons revealed significant differences between the means of all the pairs $(* * * p<0.001)$. The marine science students performed significantly better than the business administration students $\left(\mathrm{F}=70.22,{ }^{*}<0.05\right)$. The most difficult were the (c) level questions where the students had to build a frequency distribution table from the graph in order to calculate the average or to determine the shape of the distribution. The true-false questions may create a justified guessing concern, so the hypothesis of guessing was checked for each of the eight items and rejected $(* \mathrm{p}<0.05)$.

\section{Discussion}

Graphic representations are essential communication tools (Eshach, 2014).The graphs can help to visualize and interpret the variation, patterns, and trends within the data. The present study dealt with the student's ability to interpret graphs: box plots, histograms and cumulative frequency distribution graphs. In part I of this study, translating graphical representations such as box plots and histograms, into analytical concepts in descriptive statistics was examined. In part II interpreting the cumulative frequency distribution graphs was examined. The average of correct answers for the whole questionnaire was 78\%, meaning that students didn't succeed in about one fifth of the questions. In both parts of this study, there were students who had difficulties in translating the graph into analytical concepts while linking different representations. It has to be mentioned that not only novice students, but also experts have difficulties in reading graphs (e.g. Roth \& Bowen, 2001; Glazer, 2011).

The most difficult item in part I was item 6, where students could interpret the height of the graph as a bigger dispersion. They did not understand that if most of the data is close to the average, the standard deviation will be smaller. The difficulties students had in items 4, 5, 9 in part I, can be explained through intuitive rules theory (Stavy \& Tirosh, 2000). It is possible that students used here the intuitive rule Same A-Same B. Responses using the intuitive rules are given with great confidence, often persisting despite formal learning. These rules are considered to be intuitive (Stavy et al., 2006) because the students see such explanations as sufficient in addition to self-evident. 
Furthermore, responses in line with intuitive rules are made quickly (Babai, Brecher, Stavy \& Tirosh, 2006). In part II, the results revealed that more difficulties were observed in the higher level questions where students had to convert one representation into another several times. For example, in item 7 in part II, the first step is to convert the graph into a frequency distribution table and the second one is to compute the average, meaning that the visual representation is first converted into an analytic representation, and then into a numeric one. A broad range of factors influence learning (Ainsworth, 2006), so only deep understanding of each of the representations and the link between them can enable students to successfully convert one representation into another. The cognitive challenge students face in this process simultaneously representing the same data in a variety of forms, moving from one representation to another, may explain the difficulties identified in this study which also concur with other studies conducted regarding the handling of multiple representations simultaneously (e.g. Schoenfeld , Smith \& Arcavi, 1993; Arcavi, 2003; Herman, 2007).

Educators have to take this into account in designing better and more efficient learning environments. For example, students' exposure to multiple representations of the same distribution can be useful for better interpretation of statistical graphs (Lem, Onghena, Verschaffel \& Van Dooren, 2012).

\section{References}

Ainsworth, S. (1999). The functions of multiple representations. Computers \& Education, 33, 131-152. http://dx.doi.org/10.1016/S0360-1315(99)00029-9

Ainsworth, S. (2006). DeFT: A conceptual framework for considering learning with multiple representations. Learning and Instruction, 16(3), 183-198. http://dx.doi.org/10.1016/j.learninstruc.2006.03.001

Ainsworth, S. (2008). The educational value of multiple-representations when learning complex scientific concepts. In J. K. Gilbsert, M. Reiner, \& M. Nakhleh (Eds.), Visualization: Theory and practice in science education (pp. 191-208). Dordrecht, The Netherlands: Springer. http://dx.doi.org/10.1007/978-1-4020-5267-5_9

Arcavi, A. (2003). The role of visual representations in the teaching and learning of mathematics. Educational Studies in Mathematics, 52, 215-241. http://dx.doi.org/10.1023/A:1024312321077

Aoyama, K. (2007). Investigating a hierarchy of students' interpretations of graphs. International Electronic Journal of Mathematics Education, 2(3). www.iejme.com

Babai, R., Brecher, T., Stavy, R., \& Tirosh, D. (2006). Intuitive interference in probabilistic reasoning. International Journal of Science and Mathematics Education, 4, 627-639. http://dx.doi.org/10.1007/s10763-006-9031-1

Babai, R. (2010). Piagetian cognitive level and the tendency to use intuitive rules when solving comparison tasks. International Journal of Science and Mathematics Education, 8(2), 203-21. http://dx.doi.org/10.1007/s10763-009-9170-2

Bakker, A., \& Hoffmann, M.H.G. (2005). Diagrammatic reasoning as the basis for developing concepts: A semiotic analysis of students' learning about statistical distribution. Educational Studies in Mathematics, 60, 333-358. http://dx.doi.org/10.1007/s10649-005-5536-8

Bowen, G. M., \& Roth, W.-M. (2005). Data and graph interpretation practices among preservice science teachers. Journal of Research in Science Teaching, 42(10), 1063-1068. http://dx.doi.org/10.1002/tea.20086

Dori, Y.J., \& Sasson, I. (2008). Chemical understanding and graphing skills in an honors case-based computerized chemistry laboratory environment: The value of bidirectional visual and textual representations. Journal of Research in Science Teaching, 45(2), 219-250. http://dx.doi.org/10.1002/tea.20197

Eshach, H. \& Kukliansky, I. (2016). Developing of an instrument for assessing students' data analysis skills in the undergraduate physics laboratory. Canadian Journal of Physics. In Press. http://dx.doi.org/10.1139/cjp-2016-0308

Eshach, H. (2014). The use of intuitive rules in interpreting students' difficulties in reading and creating kinematic graphs. Canadian Journal of Physics, 92, 1-8. http://dx.doi.org/10.1139/cjp-2013-0369

Even, R. (1998). Factors involved in linking representations of functions. Journal of Mathematical Behavior, 17(1), 105-121. http://dx.doi.org/10.1016/S0732-3123(99)80063-7

Friel, S., Curcio, F., and Bright, G. (2001). Making sense of graphs: critical factors influencing comprehension and instructional implications. Journal for Research in Mathematics Education, 32(2), 24-158. http://dx.doi.org/10.2307/749671 
Gal, I. (2002). Adult's statistical literacy: Meaning, components, responsibilities. International Statistical Review, 70(1), 1-25. http://dx.doi.org/10.1111/j.1751-5823.2002.tb00336.x

Gal, I. (2004). Statistical literacy: Meanings, components, responsibilities. In J. Garfield \& D. Ben-Zvi (Eds.), The challenge of developing statistical literacy, reasoning and thinking (pp. 47-78). Dordrecht, The Netherlands:Kluwer. http://dx.doi.org/10.1007/1-4020-2278-6_3

Glazer, N. (2011). Challenges with graph interpretation: a review of the literature. Studies in Science Education, 47,183-210. http://dx.doi.org/10.1080/03057267.2011.605307

Herman, M. (2007). What students choose to do and have to say about use of multiple representations in college algebra. Journal of Computers in Mathematics \& Science Teaching, 26, 27-54.

Hong, Y. Y, Thomas, M. O. J. \& Kwon, O. (2000). Understanding Linear Algebraic Equations via Super-calculator Representations, Proceedings of the 24th Conference of the International Group for the Psychology of Mathematics Education, Hiroshima, Japan, 3, 57-64.

Kukliansky, I. \& Eshach, H. (2014). Evaluating a Contextual-Based Course on Data Analysis for the Physics Laboratory. Journal of Science Education and Technology 23(1), 108-115. http://dx.doi.org/10.1007/s10956-013-9456-6

Lem, S., Onghena, P., Verschaffel, L., \& Van Dooren, W. (2012). On the misinterpretation of histograms and box plots. Educational Psychology, 33, 155-174, http://dx.doi.org/10.1080/01443410.2012.674006

Petre, M., Blackwell, A. F., \& Green, T. R. G. (1998). Cognitive questions in software visualization. In J. Stasko, J. Domingue, M. Brown \& B. Price (Eds.), Software visualization: Programming as a multi-media experience (pp. 453-480). MIT Press.

Roth, W.-M., \& Bowen, G. M. (2001). Professionals read graphs: A semiotic analysis. Journal for Research in Mathematics Education, 32, 159-194. http://dx.doi.org/10.2307/749672

Schoenfeld, A. H., Smith, J. P., \& Arcavi, A. (1993). Learning: The micro genetic analysis of one student's evolving understanding of a complex subject matter domain. In R. Glaser (Ed.), Advances in Instructional Psychology (pp. 55-175). Hillsdale, NJ: Erlbaum.

Schnotz, W., \& Bannert, M. (2003). Construction and interference in learning from multiple representations. Learning and Instruction, 13, 141-156. http://dx.doi.org/10.1016/S0959-4752(02)00017-8

Stavy, R., \& Tirosh, D. (2000). How students (mis)understand science and mathematics, Intuitive rules. New York: Teachers College Press.

Stavy, R. Babai, R.. Tsamir, D., Tirosh, D.. Lin, F.L., \& McRobbie, C. (2006). Are intuitive rules universal? International Journal of Science and Mathematics Education, 4, 417-436. http://dx.doi.org/10.1007/s10763-005-9012-9

van der Meij, J., \& de Jong, T. (2006). Learning with multiple representations: Supporting students' learning with multiple representations in a dynamic simulation-based learning environment. Learning \& Instruction, 16, 199-212. http://dx.doi.org/10.1016/j.learninstruc.2006.03.007

Watson, J. M. (2006). Statistical literacy at school: growth and goals, Mahwah, NJ: Lawrence Erlbaum Associates. 